\title{
Tesouros da natureza: atividade lúdica em ambiente natural
}

\section{Nature treasures: ludic activity in natural environment}

\author{
${ }^{1}$ Raquel Lacerda Clemente Pereira diniz.felix@outlook.com.br \\ 1 Maria da Conceição Vinciprova Fonseca
}

\section{RESUMO}

O conceito de sustentabilidade, ou aproveitamento inteligente dos recursos sem comprometimento dos mesmos para as gerações vindouras, precisa ser trabalhado em todos os níveis do ensino, conforme a Lei n 9.795, de 28 de abril de 1999. Acredita-se que uma pedagogia adequada, de abordagem multidisciplinar, baseada na experiência e na participação, deverá desenvolver o respeito pela natureza, construindo uma educação voltada para uma vida sustentável.O presente artigo parte de uma pesquisa de dissertação de mestradoe apresenta uma proposta de atividade lúdica sensório-perceptiva,desenvolvida em ambiente natural com alunos do primeiro ano do ensino fundamentalcom atividades planejadas visando a potencialização dos sentidos da visão, tato, audição e olfato.Como resultado, foi observada a sintonia criada entre os alunos que participaram dessa atividade lúdicae a natureza, quando todos se mostraram receptivos às atividades propostas, o que indica estarem mergulhados em profundo sentimento de pertencimento ao ambiente natural.

Palavras-chave: Educação ambiental. Percepção ambiental. Atividadelúdica.

\section{ABSTRACT}

The concept of sustainability, or intelligent use of resources without compromising them for the next generation, needs to be improved at all levels of education, following the law $n^{\circ}$ 9.795, from the 28thof April, 1999. It is believed that the use of a multidisciplinary approach based on experience and participation should develop respect for nature, constructing an education for sustainable living.This paperis part of amaster thesis research and proposes a sensory perceptiveplayful activityconducted in the natural environment, applied to firstgrade students of elementary school, with activities planned aiming for the maximization of the senses of sight, touch, hearing and smell.As a result, the harmony created between the students who participated in this playful activity and the nature was observed, when all participants were receptive to the proposed activities, indicatingtheirsharing of a deep feeling of belonging to the natural environment.

Keywords: Environmental education. Environmental awareness.Playfulactivity 


\title{
1 INTRODUÇÃO
}

Dada arelevância dos temas que envolvem preservação ambiental e sustentabilidade, é imperativo que a criança em idade escolar tenha acesso a esses conceitos, para que os mesmos possam fazer parte da formação do seu caráter. Neste sentido, o papel do professor é de suma importância, pois por meio dele,podem ser traçadas estratégias utilizando práticas interdisciplinares capazes de promover uma educação ambiental mais eficiente,contribuindo, assim, na construção de uma comunidadeque tenha consciência de suas decisões e da atual realidade do nosso planeta (JACOBI, 2005).

A região de Volta Redonda, apesar de ser reconhecidamente uma área voltada a atividades industriais, também possui áreas de preservação ambiental, que devem ser exploradas e utilizadas no processo educativo, promovendo a sensibilização e a compreensão do pertencimento ao meio ambiente.

Diante do exposto,pensamosa possibilidade de usar uma área local protegida e desenvolver ali atividades lúdicas com crianças.Nopresente artigo, apresentamosa aplicação de uma atividade lúdica sensorialem espaço não formal - no caso, uma área de preservação ambiental -com alunos do primeiro ano do ensino fundamental. A atividade trabalha aspectos visuais, sonoros, táteis e olfativos, visando atingir um dos objetivos da educação ambiental, que é fazer com que os alunos se sintam como parte integrante do meio ambiente, valorizando os conceitos e condutas ligadas à sustentabilidade.

A respeito do conceito de sustentabilidade, Jacobi (2003) afirmaque

\begin{abstract}
a ideia de sustentabilidade implica a prevalência da premissa de que é preciso definir limites às possibilidades de crescimento e delinear um conjunto de iniciativas que levem em conta a existência de interlocutores e participantes sociais relevantes e ativos por meio de práticas educativas e de um processo de diálogo informado, o que reforça um sentimento de co-responsabilidade e de constituição de valores éticos. (JACOBI, 2003, p. 7)
\end{abstract}

Tristão (2005) vai mais além ao argumentar que

a sustentabilidade emerge como subversão à ordem econômica dominante e como fruto da insatisfação humana contra um modelo falido de desenvolvimento cunhado na racionalidade cognitivo-instrumental. Inscreve-se numa racionalidade mais aberta à imprevisibilidade e se estabelece na compreensão de uma realidade complexa, de uma interdependência entre os processos.(TRISTÃO, 2005, p. 5)

Entendemos que a atual crise ambiental está diretamente relacionada aos meios de produção e de consumo do sistema capitalista, e a educação,como um todo, encontra-se influenciada por este modelo de desenvolvimento socioeconômico baseado nopensamento cartesiano, que se impõe globalmente. Sendo assim, há uma necessidade de subverter tal modelo imposto com o domínio do seu discurso.

Diante desta realidade, o termo "sustentabilidade" tornou-se importante para pensar não só o planeta, mas também a educação. De acordo com Gadotti (2002, p. 37), “um tema portador de um projeto social global e capaz de reeducar nosso olhar e todos os nossos sentidos, capaz de reacender a esperança num futuro possível, com dignidade, para todos.”

Sabe-se também que crianças em idade escolar necessitam de atividades atraentes e significativas, que estimulem a aprendizagem, visando compreender e assimilar ideiascom nível maior de abstração ou complexidade, relacionadas aos temas que envolvam a educação ambiental. (REDIN, 2000)

O lúdico exerce uma influênciapositiva emtodas as fases do desenvolvimento infantil. A brincadeira, que deve ser uma ação prazerosa, faz parte da essência da infância e é, portanto, uma necessidade importante, tanto quanto comer e vestir.(ABERASTURY, 2007) 
Dentro da escola, constitui-se em instrumento facilitador de aprendizagem, e o educador que se propõem a utilizar essa ferramenta deverá atuar como mediador, explorando o momento deforma consciente, direcionando as atividades de maneira a estimular a produção doconhecimento.De acordo com Kishimoto(1999), a experiência lúdica relaciona-secom a intencionalidade e liberdade de ação do sujeito:

... quando as situações lúdicas são intencionalmente criadas pelo adulto com vistas a estimular certos tipos de aprendizagem surge a dimensão educativa. Desde que sejam mantidas as condições para expressão do jogo, ou seja, a ação intencional da criança para brincar, o educador está potencializando as situações de aprendizagem. (KISHIMOTO, 1999, p. 38)

É preciso, portanto, desenvolver ações educativascotidianas capazesde fazer sentido e criar interfaces para o exercício de uma educação ambientalque favoreça o desenvolvimento de uma nova consciência. Devemos pensar não somente em ações que explorem as belezas do meio ambiente, mas também naquelas que tenham o objetivo de desenvolver um sentimento de ligação com essas áreas, levando à sensação de pertencimento em relação ao meio ambiente, o que reforça a responsabilidade pela manutenção da vida planetária.

Como já citado anteriormente, a região de Volta Redonda é reconhecidamente uma área voltada para as atividades industriais. Entretanto, também possui áreas de preservação ambiental que devem ser conhecidas e estudadas para que asquestõesambientais possam ser compreendidas, servindo hoje como um contraponto ao paradigma local, de indústria e tecnologia.É importante o desenvolvimento de ações voltadas às questões ambientais, visando à formação de sujeitos conscientizados quanto a questões de ecologia, responsabilidade e sustentabilidade, diante da necessidade de levar o aluno a perceber-se como parte integrante do meio ambiente.

Desse modo, apoiados no exposto, entendemos que o desenvolvimento de atividades lúdicas sensório-perceptivas realizadas em ambiente natural pode facilitar o desenvolvimento e execução de ações em educação ambiental.Tais atividades ajudariam no desenvolvimento da percepção dos alunos, tornando-os observadores atentos do lugar ao qual pertencem e dessa forma contribuindo para que o despertar de um sentimento de ligação com a natureza. Daí aorganização de uma visita a um espaço de proteção ambiental na cidade de Volta Redonda, RJ, de modo a apresentar aos alunos uma atividade lúdica em ambiente natural, baseada em aspectos visuais, sonoros, táteis e olfativos, que os leve a sentirem-se parte do meio ambiente, iniciando sua educação ambiental.

\section{METODOLOGIA}

Para que este objetivo pudesse ser atingido, os alunos foram submetidos a procedimentos simples envolvendo os sentidos, de modo que as diferentes nuances da natureza pudessem ser apreendidas. Para tal, foi selecionada uma atividade lúdica sensório-perceptiva originalmente apresentada por Cornell (2008),que registra: "Por várias vezes constatei que, se o primeiro encontro das pessoas com algum elemento da natureza for positivo e feliz, elas se tornarão suas defensoras ou do ambiente do qual fazem parte” (CORNELL, 2008, p.121).

A aplicação da atividade aconteceu com duas turmas de alunos do primeiro ano do ensino fundamental e em momentos diferentes, perfazendo um total de 44 alunos, com 22 alunos por turma. Antes de sair com cada turma, a professora-pesquisadora conversou com os alunos sobre a proposta da ida ao Parque Municipal de Volta Redonda, RJ, que faz parte de uma área de proteção ambiental. As crianças ficaram animadas com a possibilidade de fazer uma atividade ao ar livre.

Seguindo recomendação do Comitê de Ética, todos os sujeitos participantes foram codificados para afiançar seu anonimato, segundo garantia apresentada e expressa em documento, o Termo de Consentimento Esclarecido, e de posse de autorização preenchida pelos responsáveis legais após o esclarecimento quanto aos procedimentos do estudo e sua finalidade. 
Adotou-se a metodologia da pesquisa-ação que, segundo Engel (2000), é uma maneira de se fazer pesquisa em que o sujeito deseja melhorar a compreensão da sua prática, ou seja, procura unir a pesquisa à ação com o intuito de desenvolver o conhecimento e a compreensão como parte da prática.

\section{RESULTADOS}

A atividade lúdica sensório-perceptiva,aqui denominada “Tesouros da Natureza”,foi adaptada para a realidade do local e levou em conta ascaracterísticas das turmas participantes, alunos de primeira série do ensino fundamental. A atividade possibilitauma experiência perceptiva através da visão, tato, audição e olfato, com o objetivo de estimular a criatividade e aguçar a atenção dos alunos. De acordo com Neiman (2007), a percepção e a própria educação devem possibilitar a expansão da consciência por meio do envolvimento afetivo das pessoas com a natureza e a cultura local.

Para a realização da atividade, os alunos receberam sacos de TNT para que pudessem encontrar e coletar, no ambiente selecionado para a pesquisa, elementos da natureza pedidos pela professora-pesquisadora. Após o tempo determinado para a coleta, aproximadamente 15 minutos, os alunos se reuniram para mostrar o que conseguiram coletar e, em seguida, devolveram os elementos ao lugar onde foram encontrados. Por isso foram selecionados somente elementos que pudessem ser recolocados com segurança e que não causassem danos aos alunos.São exemplos dos elementos da natureza:uma folha grande, uma folha pequena, sementes, pedras pequenas e galho pequeno no chão.

A aplicação da atividade aconteceu no mesmo dia para as duas turmas, mas em horários diferentes. Chegamos ao Parque às 14h00min com a primeira turma e às 15h30min com a segunda turma. Saímos do ônibus escolar e as crianças foram organizadas em duas filas, uma de meninos e a outra de meninas, cada fila com duas professoras auxiliando.

Com o intuito de estimular a atenção, a concentração e a disciplina, foi pedido às crianças, no início da caminhada até a área selecionada,que fizessem o mínimo de ruído possível para que pudessem perceber os sons e cheiros vindos da floresta. O Parque estava praticamente vazio, por isso foi possível ouvir os sons da natureza e sentir o cheiro da vegetação.

\section{Figura 1 - Detalhe da trajetória até o local selecionado para o desenvolvimento da atividade sensório- perceptiva, área do zoológico municipal de Volta Redonda, RJ, no dia 09/06/2015.}

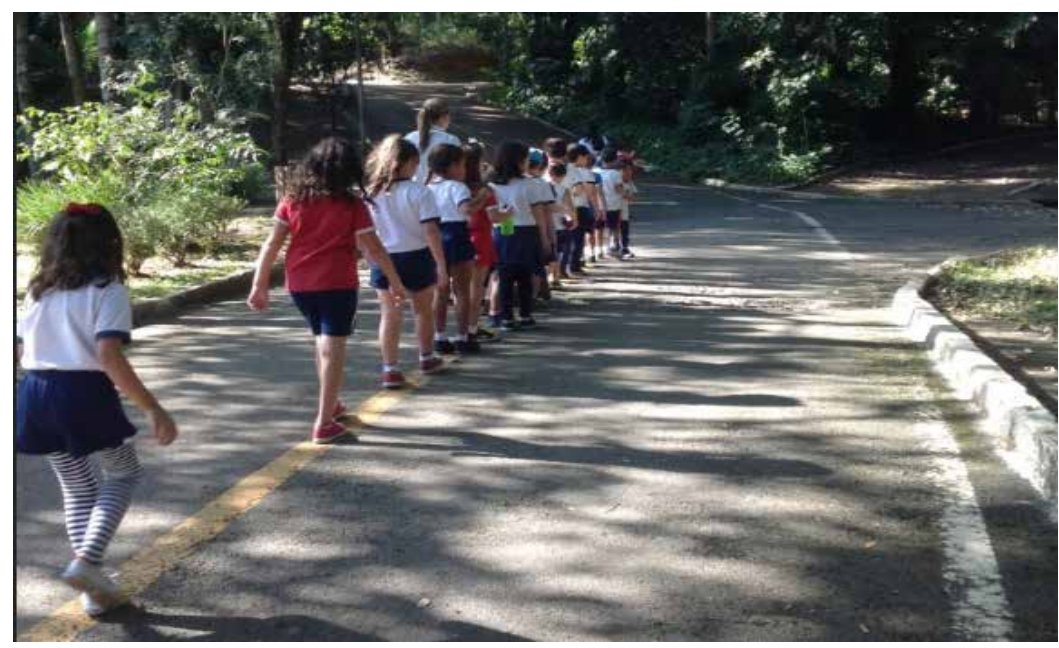

Fonte: dos autores, 2015. 
Percebe-se aqui uma característica interessante do aproveitamento das condições locais para facilitação dos procedimentos. A linha amarela no centro do caminho favoreceu a orientação da professora-pesquisadora quanto a manter a ordem e a concentração dos alunos.

No caminho até a área escolhida para a atividade há uma faixa amarela pintada no chão, que foi aproveitada para estimular a imaginação das crianças. Então,imaginamos que essa faixa indicava o caminho que deveríamos seguir para encontrarmos um lugar secreto, que ninguém conhecia, e dessa maneira não nos perderíamos na floresta, pois este seria também o caminho de volta para o ônibus.

As crianças seguiram atentamente pela faixa e sempre falavam quando ouviam algum som conhecido ou diferente, assim como apontavam algum inseto ou animal (borboleta, pássaro, mico) que viam. Algumas crianças disseram ter ouvido som de “cobra e tigre”, o que é uma indicação de estarem mergulhadas no processo imaginativo.

Chegando à área escolhida, fizemos uma roda e nos sentamos em pequenos tapetes, assim pudemos observar ao redor as árvores, o céu muito azul, ouvir pássaros, grilos, sentir a temperatura amena e o cheiro da grama, que estava úmida. Alguns alunos fizeram posição de meditação.

\section{Figura 2 - Detalhe do momento em que foi contada a história baseada no livro de José de Saramago “A Maior Flor do Mundo”, com o objetivo de concentrar o grupo para a realização da atividade “Tesouros da Natureza”.}

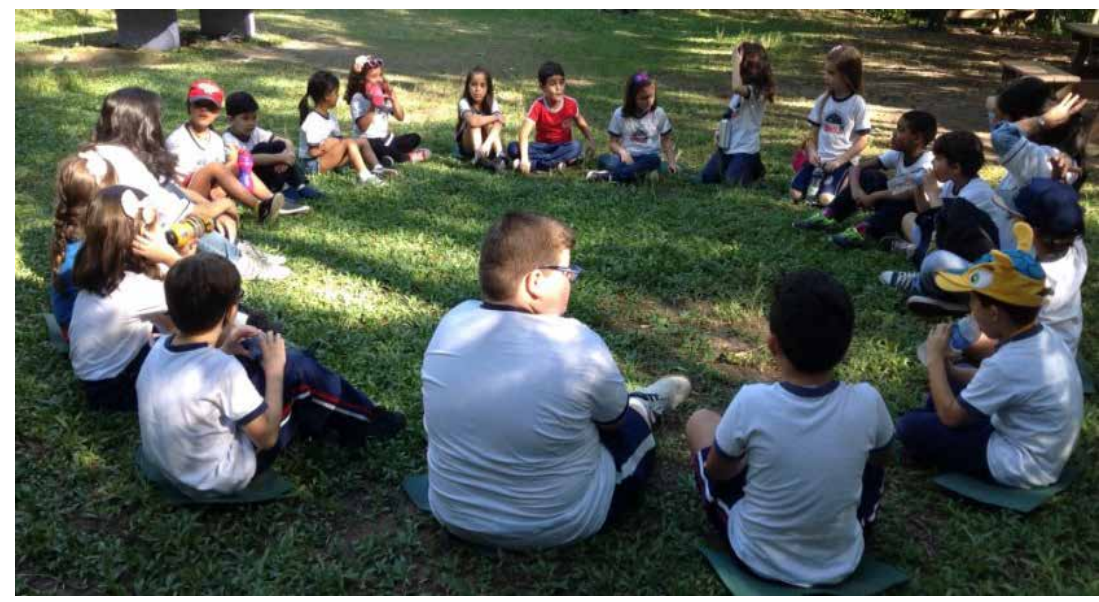

Fonte: dos autores, 2015.

Em seguida, quando todos estavam relativamente relaxados, a professora-pesquisadora começou a contar uma história baseada no livro “A Maior Flor do Mundo”,de José Saramago,com o objetivo de obter concentração do grupo para a realização da atividade “Tesouros da Natureza”. As crianças ouviram atentamente, algumas fizeram perguntas no meio da história, como: “e os pais do menino?”, “o menino podia ir até o rio buscar água para a flor?”

Após a narrativa, foi explicado que cada um imaginaria ser o menino da história e que iríamos explorar o local ao nosso redor e descobrir, assim como o menino, os tesouros escondidos na natureza. Iríamos fazer uma espécie de caça ao tesouro. As crianças ficaram animadas, principalmente porque foi distribuído um saquinho de TNT para cada uma, para que pudessem guardar os tesouros encontrados. Algumas crianças, ansiosas, anteciparam o fechamento da atividade e perguntaram se poderiam levar os tesouros para casa. 
Figura 3 - Momento em que a turma foi explorar o local para a realização da atividade denominada “Tesouros da Natureza”.

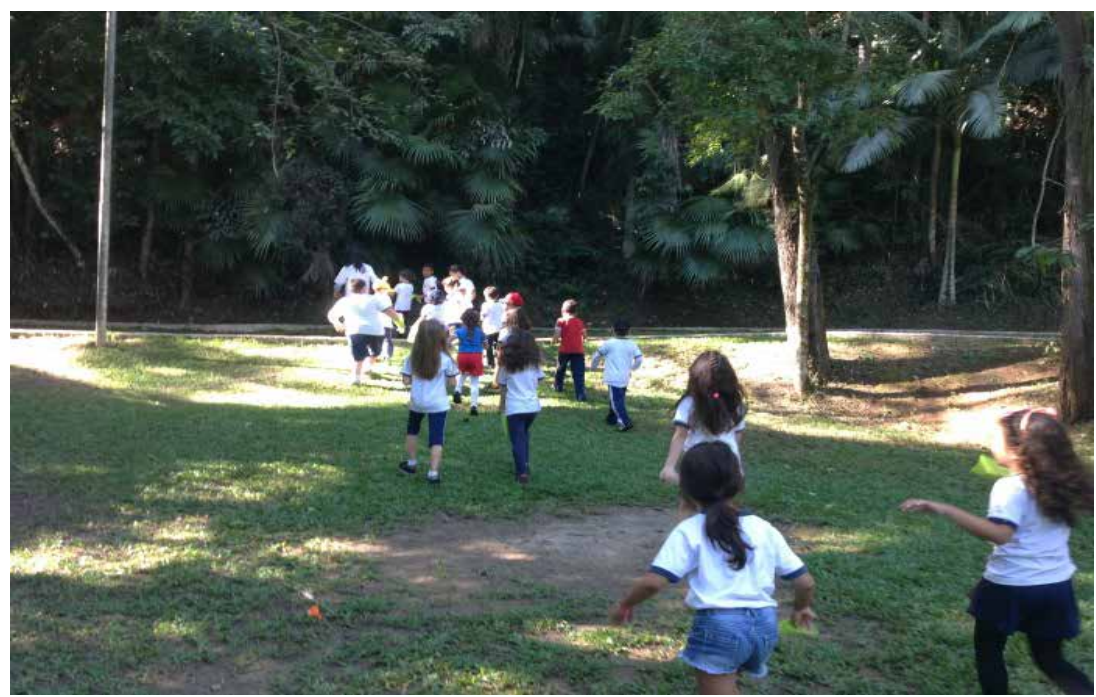

Fonte: dos autores, 2015.

Foram distribuídos saquinhos de TNT para que os alunos pudessem coletar e guardar os elementos da natureza.

Voltamos para a estrada e, tendo a faixa amarela como guia, imaginamos atravessar um rio, assim como o menino da história, chegando ao "lugar desconhecido" onde encontraríamos os tesouros.

Figura 4 - Momento em que os alunos coletavam os "tesouros" da natureza, solicitados pela professorapesquisadora.

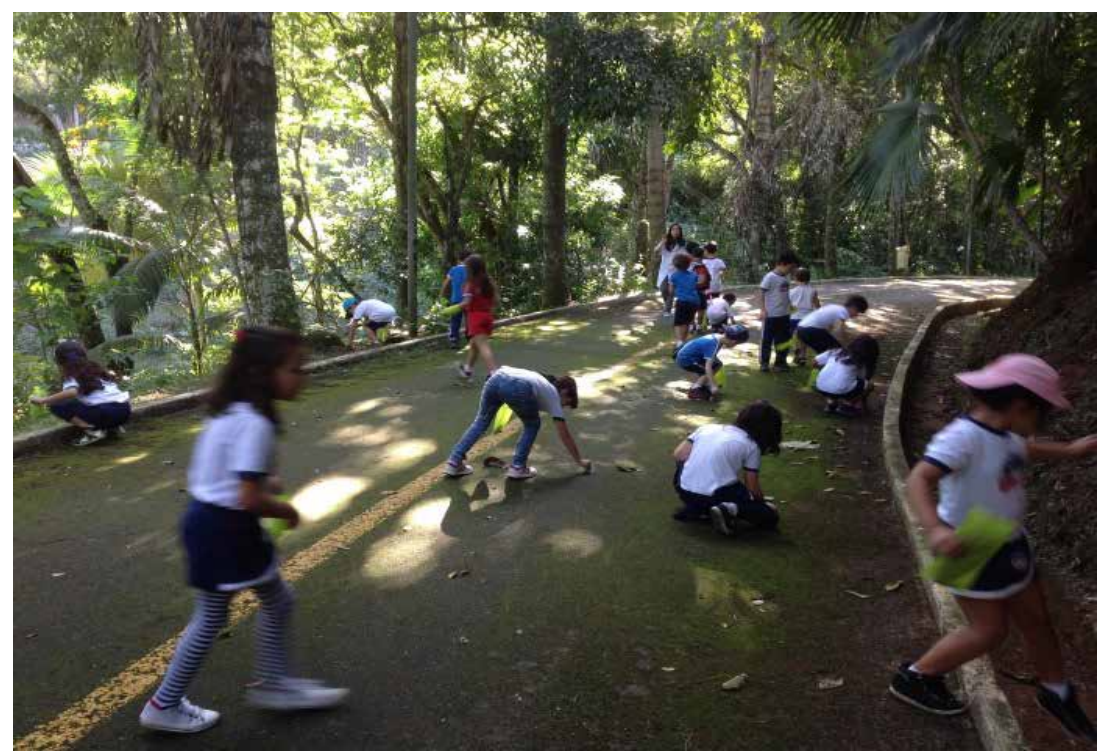

Fonte: dos autores, 2015.

Foi pedido que continuassem prestando atenção ao redor. Ao sinal da professora-pesquisadora, as crianças procuraram elementos da natureza que estavam pelo chão, tais como folhas pequenas, galhos secos, pedrinhas, sementes e flores caídas. Todos ficaram entusiasmados e pegaram tudo o que foi solicitado, guardando nos saquinhos. 
Terminado o trajeto e a coleta, foi pedido que retornassem à faixa amarela segurando os saquinhos para que, com o mínimo de ruído possível eprestando atenção aos sons da floresta, voltássemos ao local onde deixamos os tapetes.

\section{A Figura 5 - Finalização da atividade quando foi pedido aos alunos que escolhessem um de seus “tesouros" para levar para casa. $O$ restante foi devolvido para a "natureza”, sendo colocado próximo a uma árvore.}

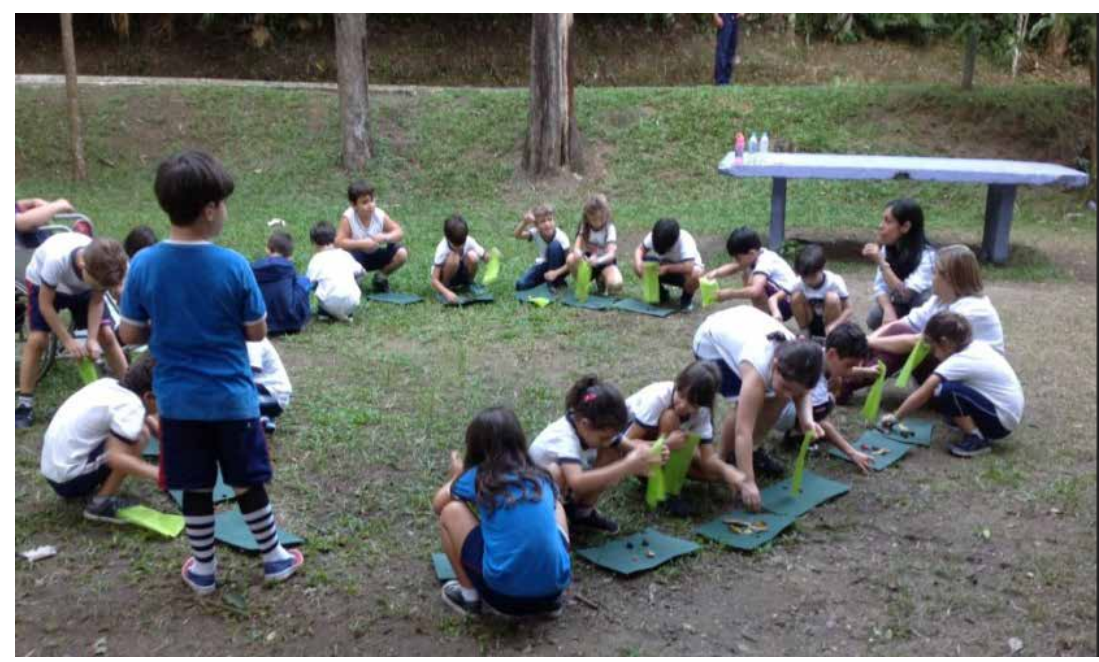

Fonte: dos autores, 2015

Chegando ao local, foi pedido que cada aluno despejasse seus “tesouros” em cima do tapete, de modo que pudessem observar e escolher apenas um para guardar no saquinho e levar para casa.

O restante dos “tesouros” deveria ser colocado debaixo de uma árvore, ou seja, ser devolvido para a natureza. Algumas crianças tiveram dificuldades em escolher apenas um “tesouro”; queriam levar tudo. Foi explicado que seria levado para casa apenas o necessário para guardar de lembrança, e que o restante deveria ser deixado para os próximos grupos que ali quisessem fazer atividades junto à natureza. Após alguns minutos de reflexão, escolheram apenas um elemento da natureza. Algumas crianças levaram os galhos, outras, as folhas e algumasescolheram a semente para plantar em casa e ver qual a planta que ali nasceria.

Terminada a atividade, voltamos para o ônibus da mesma maneira que chegamos, ou seja, em fila, caminhando na faixa amarela, prestando atenção nos sons ao redor, mas agora com os “tesouros” da natureza nas mãos e, esperamos, na memória e no coração.

\section{CONSIDERAÇÕES FINAIS}

Na busca por sociedades ambientalmente mais responsáveis, encontramos na educação ambiental uma estratégia para alcançar esse objetivo, e a escola é o espaço ideal para o desenvolvimento de ações que estimulam o sonhar com mudanças possíveis. Porém, o desafio écomo inserir a prática da educação ambiental naescola, de maneira eficaz e envolvente, através de atividades desenvolvidas no contexto escolar com o objetivo de estimular nos alunos sentimentos positivos, que posteriormente possamgerar atitudes positivas em relação ao ambiente em que vivemos.

Sendo assim, o desenvolvimento daatividade lúdica sensório-perceptiva apresentada se deu a partir do interesse em saber o quanto a potencialização dos sentidos (visão, audição, tato e olfato)dos alunos da série inicial do ensino fundamental poderia servir de auxílio para despertar uma consciência ecológica mais ampla, já que um dos objetivos da educação ambiental é fazer com que os alunos se sintam como parte integrante do meio ambiente. 
O desenvolvimento e a aplicação da atividade lúdica sensório-perceptiva ocorreram de forma prazerosa, na medida em que promoveram o engajamento entre a professora-pesquisadora e os alunos.

A visita à área de preservação ambiental onde foi aplicada a atividade proporcionou aos alunos momentos de contato e interação com a natureza. A possibilidade de participar de uma atividade ao ar livre criou uma atmosfera alegre entre os alunos, sendo percebida, de maneira mais evidente, a espontaneidade da infância. A sintonia criada entre os alunos das turmas que participaram dessa experiência com a natureza foi observada quando todos se mostraram receptivos às atividades propostas, o que indica estarem mergulhados em profundo sentimento de pertencimento ao ambiente natural.

Essasobservações corroboram a importância de atividades sensório-perceptivas em ambiente natural, na inserção de ações,na escola,que visem o desenvolvimento da percepçãoambiental dos alunos,promovendo a compreensão da importância do meio ambiente e de cada um de seus componentes para o equilíbrio planetário, e assim facilitando ainiciação dessas crianças na educação ambiental.

\section{REFERÊNCIAS}

ABERASTURY, Arminda, A criança e seus jogos. Porto Alegre: Artes Médicas, 2007

BRASIL. Lei n 9.795, de 28 de abril de 1999. Estabelece a Política Nacional de Educação Ambiental. Diário Oficial da União, Brasília, DF. Seção 1, p.1.

CORNELL, J. Vivências com a natureza. São Paulo: Aquariana, 2008.

ENGEL, G. I. Pesquisa-ação. Educar. Curitiba,Editora da UFPR, n. 16, p. 181-191, 2000.

GADOTTI, M. Boniteza de um sonho: ensinar-e-aprender com sentido. São Paulo: Ed. Cortez, 2002.

JACOBI, P. Educação Ambiental, cidadania e sustentabilidade.Cadernos de Pesquisa, n.118, mar., 2003. Disponível em: <http://www.scielo.br/pdf/cp/n118/16834.pdf>. Acesso em: 10 jan. 2015.

JACOBI, P. Educação Ambiental:o desafio da construção de um pensamento crítico, complexo. Educação e Pesquisa, v. 31, n. 2, p. 233-250, maio/ago. 2005. Disponível em: < http://www.scielo.br/pdf/ep/v31n2/a07v31n2. pdf>. Acesso em: 23 nov. 2015.

KISHIMOTO, T. M.Jogo, brinquedo e educação. São Paulo: Ed. Cortez, 1999.

NEIMAN, Z. A Educação Ambiental através do contato dirigido com a natureza. 2007. 138f. Tese de doutorado - Psicologia Experimental, USP, São Paulo, 2007.

PEREIRA, R. L. C. Meio ambiente, a escola e a criança: estreitando laços. 2016. 68f. Dissertação de mestrado - Ensino em Ciências da Saúde e do Meio Ambiente, UniFOA, Centro Universitário de Volta Redonda, Rio de Janeiro, 2016.

REDIN, E.O espaço e o tempo da criança. 3 ed. Porto Alegre: Mediação, 2000.

SARAMAgO, J. de. A maior Flor do Mundo. 1ed. São Paulo: Cia. Das Letrinhas, 2001.

TRISTÃO, M. Tecendo os fios da educação ambiental: o subjetivo e o coletivo, o pensado e o vivido. Educação e Pesquisa, São Paulo, v. 31, n. 2, p. 251-264, maio/ago 2005. 